\title{
Guillain-Barré Syndrome as a Neurological Complication of COVID-19 Infection: A Case Series and Review of the Literature
}

\author{
Hossein Mozhdehipanah, Sepideh Paybast ${ }^{\star}$, Reza Gorji \\ Department of Neurology, Bou Ali Sina Hospital, Qazvin University of Medical Sciences, Qazvin, Iran
}

\begin{abstract}
The novel coronavirus disease 2019 (COVID-19) is a global pandemic. Although the main clinical manifestations of the COVID-19 infection have confined to the respiratory system, there is some evidence suggesting the neuro-invasive potential of the COVID-19. There are limited reports of Guillain-Barré syndrome (GBS) as a peripheral nervous system complication of COVID-19 infection. We described four patients with COVID-19 infection who developed acute polyneuropathy with a final diagnosis of Guillain-Barré syndrome. COVID-19 may have the potential to invade the peripheral nervous system. GBS, as one of the critical neurological complications of COVID-19, could be considered as a post-infectious event.

Keywords: Novel corona-virus; COVID-19; Neurological complication; Guillain-Barré syndrome.
\end{abstract}

\section{*Correspondence to}

Sepideh Paybast, Assistant professor, Department of Neurology, Bou Ali Sina Hospital, Qazvin University of Medical Sciences, Qazvin, Iran. Tel: +989125967487 ,

Fax: +982833356696, Email:

Sepideh.paybast@yahoo.com, S.paybast@qums.ac.ir

Published online June 21, 2020

Citation: Mozhdehipanah H, Paybast S, Gorji R,Guillain-Barré Syndrome as a Neurological Complication of COVID-19 Infection: A Case Series and Review of the Literature. Clin Neurosci J. 2020;7(3):156-161. doi:10.34172/icnj.2020.18.

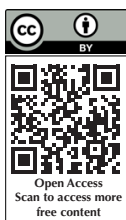

\section{Introduction}

The novel coronavirus disease 2019 (COVID -19) has first reported in December 2019 in Wuhan, China, with a cluster of unexplained pneumonia, which soon has turned into a global health concern. the World Health Organization (WHO) has recently declared a global pandemic, affecting more than 4 million cases worldwide. ${ }^{1,2}$ Although the main clinical features of the COVID-19 infection have confined to the respiratory tracts, there is evidence suggesting the virus potential to invade the central and peripheral nervous system. To the best of our knowledge, eight cases of COVID-19 associated Guillain-Barré syndrome (GBS) have been reported from China, Iran, and Italy so far. ${ }^{3,4}$ Herein, we aimed to report four GBS cases in association with COVID-19 to highlight the peripheral nervous system's involvement in COVID-19 infection and provide a comprehensive review of the peripheral nervous system complications of the newly emerging virus.

\section{Case Presentation \\ Case One}

A 38-year-old man admitted to the emergency department with a 5-day history of progressive symmetric ascending paresthesia and bilateral facial droop following upper respiratory infection 3 weeks before admission. On examination, the patient was alert and conscious. His vital signs revealed body temperature $36.5^{\circ} \mathrm{C}$, blood pressure $175 / 85 \mathrm{~mm} \mathrm{Hg}$, respiratory rate of 16 breaths per minute, pulse rate 75 beats per minute, and oxygen saturation of $99 \%$. The systemic examination was normal. Neurological examination was notable for bilateral complete lower motor neuron type facial paralysis and mildly dysarthric speech.

The motor examination revealed a normal tone and force regarding the medical research council (MRC) score. Deep tendon reflexes were generally absent. Sensory examination indicated a decrease in all sensation modalities in four limbs affecting the distal parts up to ankle and elbow joints. The Romberg test is positive when the patient closed his eyes. The remainder of the examination was unremarkable.

With suspicion of acute demyelinating polyneuropathy, the patient transferred to the intensive care unit (ICU). All conventional diagnostic tests were normal, including electrocardiograms, routine blood chemistry, C-reactive protein (CRP), erythrocyte sedimentation rate (ESR), chest, and brain-computed tomography (CT). Additionally, due to the COVID-19 pandemic, the polymerase chain reaction (PCR) assay of throat swab sample was performed for COVID-19, which was positive. The cerebrospinal fluid (CSF) puncture

(C) 2020 The Author(s). This is an open access article distributed under the terms of the Creative Commons Attribution License (http:// creativecommons.org/licenses/by/4.0/), which permits unrestricted use, distribution, and reproduction in any medium, provided the original work is properly cited. 
revealed normal glucose and cell count and $139 \mathrm{mg} / \mathrm{dL}$ protein. CSF HSV serology and gram stain and culture were negative. The nerve conduction study (NCS) (Tables 1 and 2) has performed, which yielded a considerable reduction in the compound motor action potentials (CMAP) amplitude with prolonged distal latency and reduced conduction velocity of tibial nerves in a range of demyelinating process and absent peroneal, median and ulnar nerves CMAP. The ulnar and median sensory nerve action potential (SNAP) were absent. However, the sural nerve was spare.

Additionally, $\mathrm{F}$ and $\mathrm{H}$ waves were absent. Electromyography (EMG) showed reduced recruitment in all limbs without evidence of spontaneous activity. The findings were consistent with acute demyelinating polyradiculoneuropathy. On hospital day 3 , the patient developed the bulbar and autonomic features as he was unable to swallow with blood pressure instability and tachycardia. Additionally, mild weakness in lower limbs appeared. Treatment started with therapeutic plasma exchange (TPE).

We did a total of five sessions of TPE (alternate days). One standard TPE session was 2.5 plasma volume exchange using $5 \%$ albumin as a replacement fluid. Furthermore, labetalol by intravenous bolus administered to control the sympathetic nervous system over-reactivity, which successfully controlled over 24 hours. The patient was discharged from the hospital three weeks later with a significant improvement of the symptoms except for mild bilateral facial paresis.

\section{Case Two}

A 14-year-old girl admitted to the emergency department with symptoms of acute progressive ascending quadriparesis and lower limb weakness since three days before admission following an upper respiratory infection. On physical examination, the patient was afebrile with blood pressure $110 / 75 \mathrm{~mm} / \mathrm{Hg}$, heart rate 73 beats/minute, respiratory rate 16/minute, and oxygen saturation of $99 \%$. The neurological examination was notable for weakness in lower limbs with an MRC scale of $4 / 5$ in both proximal and distal muscles. The deep tendon reflexes were hypoactive in upper limbs and absented in lower limbs, respectively. The sensory examination was notable for a decreased light touch, position, and vibration sensation in all distal limbs up to ankle and elbow joints. The patient was ambulatory. However, she became ataxic with closed eyes.

The patient admitted to the ICU. All the ancillary examinations were within normal limits except for the albuminocytological dissociation in the CSF and positive PCR assay of throat swab sample for COVID-19. As the patient did not consent to EMG-NCS, we made the GBS diagnosis based on Brighton criteria levels $2 .^{5}$ In the following, intravenous immunoglobulin (IVIG, $20 \mathrm{~g}$ IV daily for 5 days) has instituted, leading to complete recovery of the symptoms except for generalized hyporeflexia.

\section{Case Three}

A 55-year-old woman admitted to the hospital with a fiveday history of non-productive cough, fever, myalgia, and progressive dyspnea. The past medical history was notable for chronic obstructive pulmonary disease (COPD). Upon admission, her vital signs revealed body temperature $37.5^{\circ} \mathrm{C}$, blood pressure $140 / 85 \mathrm{~mm} \mathrm{Hg}$, respiratory rate of 26 breaths per minute, pulse rate 126 beats per minute, and oxygen saturation of $56 \%$. The Meningeal irritation signs were negative.

The laboratory examination revealed leukocytosis with lymphopenia and elevated ESR and CRP. Other conventional laboratory tests were within normal limits.

Table 1. Motor Nerve Conduction Study

\begin{tabular}{|c|c|c|c|c|c|c|c|c|c|}
\hline \multirow{2}{*}{ Nerve } & & \multicolumn{2}{|c|}{ Latency (ms) } & \multicolumn{2}{|c|}{ Amplitude (micro V) } & \multicolumn{2}{|c|}{ Conduction Velocity $(\mathrm{m} / \mathrm{s})$} & \multirow{2}{*}{$\frac{\text { F Wave }}{\text { Right }}$} & \multirow{2}{*}{$\frac{\text { H Wave }}{\text { Left }}$} \\
\hline & & Right & Left & Right & Left & Right & Left & & \\
\hline Median & & Absent & Absent & Absent & Absent & Absent & Absent & Absent & - \\
\hline Ulnar & & Absent & Absent & Absent & Absent & Absent & Absent & Absent & - \\
\hline \multirow{2}{*}{ Tibial } & Ankle & 9.5 & 9.9 & 0.5 & 0.4 & \multirow{2}{*}{24} & \multirow{2}{*}{23} & \multirow{2}{*}{ Absent } & \multirow{2}{*}{ Absent } \\
\hline & Popliteal fossa & 27.7 & 28.1 & 0.0 & 0.0 & & & & \\
\hline Peroneal & & Absent & Absent & Absent & Absent & Absent & Absent & Absent & Absent \\
\hline
\end{tabular}

Table 2. Sensory Nerve Conduction Study

\begin{tabular}{|c|c|c|c|c|c|c|}
\hline \multirow{2}{*}{ Nerve } & \multicolumn{2}{|c|}{ Latency (ms) } & \multicolumn{2}{|c|}{ Amplitude (micro V) } & \multicolumn{2}{|c|}{ Conduction Velocity $(\mathrm{m} / \mathrm{s})$} \\
\hline & Right & Left & Right & Left & Right & Left \\
\hline Median & Absent & Absent & Absent & Absent & Absent & Absent \\
\hline Ulnar & Absent & Absent & Absent & Absent & Absent & Absent \\
\hline Sural & 3.0 & 3.0 & 10 & 10 & 55 & 55 \\
\hline
\end{tabular}


The chest CT revealed severe bilateral ground glass, consistent with COVID-19 infection. The PCR assay performed, which confirmed the diagnosis. The patient was transferred to the ICU and started on hydroxy chloroquine (HCQ; $200 \mathrm{mg}$ twice a day for 10 days) and Kaletra (200/50 two tablets twice a day for 5 days).

Additionally, the patient got intubated due to a progressive decrease in $\mathrm{O} 2$ saturation. Subsequently, the clinical symptoms improved. She was separated from the ventilator and transferred to the ward receiving O2 with a mask. All of a sudden, on day 26, the patient developed acute progressive lower limb weakness. On physical examination, the vital signs were normal. The neurological examination was notable for limbs weakness an MRC scale of $3 / 5$ in both proximal and distal of the lower extremities and 4/5 in proximal of the upper extremities. Deep tendon reflexes were generally absent, and the sensory examination revealed decreased pinprick and vibration sensations in distal extremities. The patient was non-ambulatory.

Additionally, no remarkable sign observed in cranial nerves. With suspicion of acute polyneuropathy, the patient underwent lumbar puncture, which revealed average glucose, cell count, and protein $(57 \mathrm{mg} / \mathrm{dL}$ protein). The electro-diagnostic study (Tables 3 and 4) yielded a considerable reduction in CMAP amplitude of median and ulnar nerves with average distal latency and conduction velocity and absent tibial and peroneal nerves CMAP. The ulnar, median, and sural SNAP were absent. Additionally, $\mathrm{F}$ and $\mathrm{H}$ waves were absent. EMG showed reduced recruitment in all limbs without evidence of spontaneous activity. The findings were consistent with acute axonal motor and sensory polyneuropathy (AMSAN). The patient started on intravenous immunoglobulin (20 g IV daily for five days). Unfortunately, on the third day of IVIG treatment, she developed acute respiratory distress syndrome (ARDS), which eventually led to her decease.

\section{Case Four}

A 66-year-old woman with a history of diabetes mellitus, hypertension, and rheumatoid arthritis admitted to the emergency department with a seven-day history of fever, non-productive cough, and severe myalgia. Given the existing pandemic, COVID-19 infection suspected. Chest CT and oropharyngeal PCR performed, which confirmed the diagnosis of COVID-19 infection. Furthermore, the laboratory examination was notable for revealed leukocytosis with lymphopenia and elevated ESR and CRP.

Consequently, the patient was transferred to the infection isolation room and received supportive care and antiviral drugs of hydroxy chloroquine (HCQ; 200 mg twice a day for ten days) and Kaletra (200/50 two tablets twice a day for 5 days) leading to partial recovery of the symptoms. Although the patient did not require intubation, she was dependent on oxygen throughout the hospitalization period. On day 30, the patient developed progressive quadriparesis. The neurological consult requested for the patient. She has noted to have $2 / 5$ strength in her lower extremities with $4 / 5$ in her upper extremities. Deep tendon reflexes were absent. Sensory examination revealed decreased light touch, position, and vibration sensation in all distal limbs up to ankle and elbow joints. However, no evidence of cranial or autonomic involvement has observed. With suspicion of GBS, she started on IVIG. The ancillary examinations performed.

The CSF puncture revealed average glucose and cell count and $89 \mathrm{mg} / \mathrm{dl}$ protein. The NCS (Tables 5 and 6) yielded a considerable reduction in the CMAP amplitude with prolonged distal latency and reduced conduction velocity of tibial and peroneal nerves and prolonged distal latency and low conduction velocity of the median and

Table 3. Motor Nerve Conduction Study

\begin{tabular}{|c|c|c|c|c|c|c|c|c|}
\hline \multirow{2}{*}{ Nerve } & \multicolumn{2}{|c|}{ Latency (ms) } & \multicolumn{2}{|c|}{ Amplitude (micro V) } & \multicolumn{2}{|c|}{ Conduction Velocity $(\mathrm{m} / \mathrm{s})$} & \multirow{2}{*}{$\frac{\text { F Wave }}{\text { Right }}$} & \multirow{2}{*}{$\frac{\text { H Wave }}{\text { Left }}$} \\
\hline & Right & Left & Right & Left & Right & Left & & \\
\hline Median & 4.1 & 4.2 & 0.9 & 1.1 & 55 & 58 & Absent & - \\
\hline Ulnar & 3.9 & 3.9 & 1.3 & 1.2 & 54 & 53 & Absent & - \\
\hline Tibial & Absent & Absent & Absent & Absent & Absent & Absent & Absent & Absent \\
\hline Peroneal & Absent & Absent & Absent & Absent & Absent & Absent & Absent & - \\
\hline
\end{tabular}

Table 4. Sensory Nerve Conduction Study

\begin{tabular}{|c|c|c|c|c|c|c|}
\hline \multirow{2}{*}{ Nerve } & \multicolumn{2}{|c|}{ Latency (ms) } & \multicolumn{2}{|c|}{ Amplitude (micro V) } & \multicolumn{2}{|c|}{ Conduction Velocity $(\mathrm{m} / \mathrm{s})$} \\
\hline & Right & Left & Right & Left & Right & Left \\
\hline Median & Absent & Absent & Absent & Absent & Absent & Absent \\
\hline Ulnar & Absent & Absent & Absent & Absent & Absent & Absent \\
\hline Sural & Absent & Absent & Absent & Absent & Absent & Absent \\
\hline
\end{tabular}


Table 5. Motor Nerve Conduction Study

\begin{tabular}{|c|c|c|c|c|c|c|c|c|c|}
\hline \multirow{2}{*}{ Nerve } & & \multicolumn{2}{|c|}{ Latency (ms) } & \multicolumn{2}{|c|}{ Amplitude (micro V) } & \multicolumn{2}{|c|}{ Conduction Velocity $(\mathrm{m} / \mathrm{s})$} & \multirow{2}{*}{$\frac{\text { F wave }}{\text { Right }}$} & \multirow{2}{*}{$\frac{\text { H wave }}{\text { Left }}$} \\
\hline & & Right & Left & Right & Left & Right & Left & & \\
\hline \multirow{2}{*}{ Median } & Wrist & 7.8 & 8.9 & 4.5 & 5.1 & \multirow{2}{*}{38} & \multirow{2}{*}{37} & \multirow{2}{*}{48} & \multirow{2}{*}{ - } \\
\hline & Elbow & 12.4 & 12.6 & 4.4 & 5.2 & & & & \\
\hline \multirow{2}{*}{ Ulnar } & Wrist & 6.2 & 5.7 & 5.8 & 5.5 & \multirow{2}{*}{35} & \multirow{2}{*}{34} & \multirow{2}{*}{49} & \multirow{2}{*}{-} \\
\hline & Elbow & 11.7 & 13.2 & 5.5 & 5.3 & & & & \\
\hline \multirow{2}{*}{ Tibial } & ankle & 9.2 & 9.9 & 1.5 & 1.4 & \multirow{2}{*}{28} & \multirow{2}{*}{27} & \multirow{2}{*}{67} & \multirow{2}{*}{43} \\
\hline & Popliteal fossa & 26.7 & 28.1 & 1.0 & 1.0 & & & & \\
\hline \multirow{2}{*}{ Peroneal } & Ankle & 8.3 & 10.1 & 0.8 & 0.6 & \multirow{2}{*}{25} & \multirow{2}{*}{26} & \multirow{2}{*}{66} & \multirow[t]{2}{*}{-} \\
\hline & Below elbow & 20.2 & 21.4 & 0.6 & 0.0 & & & & \\
\hline
\end{tabular}

Table 6. Sensory Nerve Conduction Study

\begin{tabular}{|c|c|c|c|c|c|c|}
\hline \multirow{2}{*}{ Nerve } & \multicolumn{2}{|c|}{ Latency (ms) } & \multicolumn{2}{|c|}{ Amplitude (micro V) } & \multicolumn{2}{|c|}{ Conduction Velocity $(\mathrm{m} / \mathrm{s})$} \\
\hline & Right & Left & Right & Left & Right & Left \\
\hline Median & Absent & Absent & Absent & Absent & Absent & Absent \\
\hline Ulnar & Absent & Absent & Absent & Absent & Absent & Absent \\
\hline Sural & 3.0 & 3.0 & 10 & 10 & 55 & 55 \\
\hline
\end{tabular}

ulnar nerves. The ulnar and median SNAP were absent. However, the sural nerve was spare. Additionally, $\mathrm{F}$ and $\mathrm{H}$ waves were prolonged. EMG showed reduced recruitment in all limbs without evidence of spontaneous activity. The findings were consistent with acute demyelinating polyradiculoneuropathy. A diagnosis of GBS made, and the patient started on IVIG (20 g IV daily for 5 days). She did not respond well to the treatment and eventually discharged to a rehabilitation facility for physical therapy.

\section{Discussion}

COVID-19 is an enveloped, non-segmented, positivestranded RNA virus belonging to the family Coronaviridae. Similar to severe acute respiratory syndrome-related coronavirus (SARS-CoV) and Middle East respiratory syndrome coronavirus (MERS-CoV), the primary mechanism of virus pathogenesis attributed to the cellular receptor angiotensin-converting enzyme 2 (ACE2) receptors attachment located in the nasal epithelium and lower respiratory airways are leading to respiratory symptoms. However, there is evidence suggesting the neuro-invasive potential of the virus. ${ }^{1-4,6}$ As the virus is rapidly spreading around the world, and the outbreak continues to escalate, more neurological complications will be evident. Of note, GBS is an acute immune-mediated polyradiculoneuropathy that often occurs a few days to weeks after an antecedent infection, trauma, surgery, or vaccination. The main clinical presentations are rapidly progressive, areflexic flaccid paralysis involving proximal and distal muscles relatively symmetrical. While the most common infection associated with GBS development is campylobacteriosis, viral infections have the potential to induce GBS. ${ }^{7,8}$
In this report, we described four patients with COVID-19 who developed clinical features of GBS after 21 to 30 days after the first symptoms of COVID-19. Three patients were female, and one was male. The mean age of our patients was 43 . Three patients had onset with lowerlimbs weakness and paresthesia, and one had facial paresis and paresthesia who later developed autonomic instability and mild lower-limbs weakness. Two patients developed generalized flaccid quadriplegia, and respiratory failure in that one eventually ceased despite medical therapy. CSF showed elevated protein in three patients. Electrodiagnostic studies were consistent with AMSAN in one patient, and two had a demyelinating pattern. Treatment started with IVIG in three patients, and one received a course of TPE.

Based on recently published studies, there is a possible association between GBS and COVID-19 infection. Zhao et al reported the first case of COVID-19 infection associated with GBS. They reported a 65 year-woman presenting with acute progressive lower limb weakness after returning from a trip to Wuhan. The neurological examination was compatible with symmetric polyneuropathy. The laboratory examination revealed significant lymphocytopenia, thrombocytopenia, and albuminocytological dissociation in CSF analysis. The EMG-NCS findings were consistent with acute demyelinating polyneuropathy. With a diagnosis of GBS, she was given IVIG and later on developed respiratory symptoms. Eventually, she made an excellent motor recovery after isolation and administration of antiviral and IVIG. Contrary to Zhao et al report in which their patient developed the symptoms of COVID-19 in the course of hospitalization, our patients developed the symptoms of 
GBS following COVID-19 infection suggesting the postinfectious' profile of GBS. ${ }^{9}$

Later, Sedaghat and Karimi reported a 61-year old Iranian man presenting with progressive ascending quadriparesis and bilateral facial paralysis two weeks after COVID-19 infection. The EMG-NCS findings were compatible with AMSAN. Additionally, on admission, the chest CT revealed ill-defined opacities in both lungs. The patient managed with a five-day course of IVIG. However, it should note that the prognosis of the patient has not mentioned in their report. ${ }^{10}$

Similarly, Virani et al reported a 54-years man from the United States presenting with rapidly progressive ascending paralysis leading to respiratory difficulty following upper respiratory infection and diarrhea. He tested positive for COVID-19. As the clinical scenario and neurological examination were compatible with acute polyneuropathy, the patient started on IVIG, and lumbar puncture and EMG-NCS have not performed. Their patient responded well, was weaned off from the ventilator, and eventually discharged to a rehabilitation facility for physical therapy. ${ }^{11}$

A more comprehensive report was published describing five patients with COVID-19 in association with GBS in Italy. Based on their findings, lower-limb weakness and paresthesia were the main presenting features. In terms of electro-diagnostic features, two patients had demyelinating polyneuropathy features, while three had axonal polyneuropathy. All the patients treated with IVIG. After 1 week, only one patient was able to ambulate independently and discharged from the hospital. ${ }^{12}$

The comparison of our report and the previous reports has brought in Table 7.

Regarding the increasing number of patients with COVID19 in association with GBS, especially our report of four patients in a short time, it seems, it might induct that the newly emerging virus has the potential to induce peripheral nervous system complications and it is highly necessary for clinicians to pay more attention to the neurological status of the patients.

Table 7. The Summary of Association of COVID-19 and GBS of All the Current Reports Compared to Our Report

\begin{tabular}{|c|c|c|c|c|c|c|c|c|c|}
\hline Article & Age & Sex & $\begin{array}{l}\text { Past Medical } \\
\text { History }\end{array}$ & $\begin{array}{l}\text { Onset From Initial } \\
\text { Presentation of } \\
\text { COVID }\end{array}$ & Clinical Presentation & CSF Analysis & EMG-NCS & Treatment & Prognosis \\
\hline Zhao et al $^{9}$ & 65 & Female & Negative & $\begin{array}{l}\text { The GBS presentation } \\
\text { was superior to } \\
\text { COVID-19 infection }\end{array}$ & Lower limbs weakness & $\begin{array}{l}\text { The } \\
\text { albuminocytological } \\
\text { dissociation }\end{array}$ & AIDP & IVIG & $\begin{array}{l}\text { Complete } \\
\text { recovery }\end{array}$ \\
\hline $\begin{array}{l}\text { Sedaghat and } \\
\text { Karimi }^{10}\end{array}$ & 61 & Male & $\mathrm{DM}$ & Two weeks & $\begin{array}{l}\text { Ascending quadriparesis } \\
\text { and facial paralysis }\end{array}$ & Not carried out & AMSAN & IVIG & Non mentioned \\
\hline Virani et al ${ }^{11}$ & 54 & Male & - & Ten days & $\begin{array}{l}\text { Ascending quadriparesis } \\
\text { and respiratory failure }\end{array}$ & Not carried out & $\begin{array}{l}\text { Not carried } \\
\text { out }\end{array}$ & IVIG & $\begin{array}{l}\text { Partial recovery } \\
\text { (referral to } \\
\text { rehabilitation } \\
\text { center) }\end{array}$ \\
\hline \multirow{5}{*}{ Toscano et al ${ }^{12}$} & 77 & Female & - & Seven days & $\begin{array}{l}\text { quadriparesis, facial } \\
\text { paresis, and respiratory } \\
\text { failure }\end{array}$ & $\begin{array}{l}\text { the } \\
\text { albuminocytological } \\
\text { dissociation }\end{array}$ & AMSAN & IVIG & Poor outcome \\
\hline & 23 & Male & - & Ten days & $\begin{array}{l}\text { Lower limbs paresthesia } \\
\text { with ataxia and facial } \\
\text { paralysis }\end{array}$ & $\begin{array}{l}\text { the } \\
\text { albuminocytological } \\
\text { dissociation }\end{array}$ & AMSAN & IVIG & $\begin{array}{l}\text { Mild } \\
\text { improvement }\end{array}$ \\
\hline & 55 & Male & - & Ten days & $\begin{array}{l}\text { quadriparesis, facial } \\
\text { paresis, and respiratory } \\
\text { failure }\end{array}$ & $\begin{array}{l}\text { the } \\
\text { albuminocytological } \\
\text { dissociation }\end{array}$ & AMAN & IVIG & Poor outcome \\
\hline & 76 & Male & - & 5 days & quadriparesis & Normal & AIDP & IVIG & Poor outcome \\
\hline & 61 & Male & - & Seven days & $\begin{array}{l}\text { Paraplegia, facial } \\
\text { paralysis, and } \\
\text { respiratory failure }\end{array}$ & Normal & AIDP & IVG and TPE & Poor outcome \\
\hline \multirow{4}{*}{ Our patients } & 38 & Male & HTN & Three weeks & $\begin{array}{l}\text { Quadripareshtesia and } \\
\text { facial paralysis }\end{array}$ & $\begin{array}{l}\text { albuminocytological } \\
\text { dissociation }\end{array}$ & AIDP & TPE & $\begin{array}{l}\text { Near to complete } \\
\text { recovery except } \\
\text { for facial paresis. }\end{array}$ \\
\hline & 14 & Female & Negative & There weeks & Lower limbs weakness & $\begin{array}{l}\text { albuminocytological } \\
\text { dissociation }\end{array}$ & $\begin{array}{l}\text { Not carried } \\
\text { out }\end{array}$ & IVIG & $\begin{array}{l}\text { Complete } \\
\text { recovery }\end{array}$ \\
\hline & 55 & Female & COPD & 26 days & $\begin{array}{l}\text { Generalized flaccid } \\
\text { paralysis and respiratory } \\
\text { failure }\end{array}$ & Normal & AMSAN & IVIG & $\begin{array}{l}\text { The patient } \\
\text { expired }\end{array}$ \\
\hline & 66 & Female & DM, HTN, RA & 30 days & $\begin{array}{l}\text { Generalized flaccid } \\
\text { paralysis }\end{array}$ & $\begin{array}{l}\text { albuminocytological } \\
\text { dissociation }\end{array}$ & AIDP & IVIG & $\begin{array}{l}\text { No response } \\
\text { without } \\
\text { respiratory } \\
\text { involvement }\end{array}$ \\
\hline
\end{tabular}


Although the primary mechanism of GBS formation in patients with COVID-19 is not yet well understood, it has postulated that the virus stimulates inflammatory cells producing a cascade of inflammatory cytokines, which induces immune-mediated polyneuropathy. ${ }^{13}$ However, further assessment should conduct on the mechanism of GBS in patients with COVID-19.

\section{Conclusion}

The COVID-19 infection has considered a global pandemic. Reports are suggesting a possible association between GBS and COVID-19 infection. Our report is unique in that it indicates a case series of GBS associated with COVID-19 infection and provides a comprehensive review of all the current literature focusing on COVID-19 and GBS. Of note, more cases with epidemiological data are necessary to support a causal relationship.

\section{Conflict of Interest}

The authors declare that they have no conflict of interests, and no funding has used for the manuscript.

\section{Acknowledgments}

The authors declare that they have no acknowledgment state.

\section{Ethical Statement}

Informed consent was obtained from the patients for publication of this report.

\section{References}

1. Wang C, Horby PW, Hayden FG, Gao GF. A novel coronavirus outbreak of global health concern. Lancet. 2020;395(10223):470-3. doi: 10.1016/s01406736(20)30185-9.

2. Huang C, Wang Y, Li X, Ren L, Zhao J, Hu Y, et al. Clinical features of patients infected with 2019 novel coronavirus in Wuhan, China. Lancet. 2020;395(10223):497-506. doi: 10.1016/s0140-6736(20)30183-5.

3. Tu H, Tu S, Gao S, Shao A, Sheng J. Current epidemiological and clinical features of COVID-19; a global perspective from China. J Infect. 2020;81(1):1-9. doi:10.1016/j. jinf.2020.04.011

4. Ahmad I, Rathore FA. Neurological manifestations and complications of COVID-19: a literature review. J Clin Neurosci. 2020;77:8-12. doi: 10.1016/j.jocn.2020.05.017.

5. Sejvar JJ, Kohl KS, Gidudu J, Amato A, Bakshi N, Baxter $\mathrm{R}$, et al. Guillain-Barré syndrome and Fisher syndrome: case definitions and guidelines for collection, analysis, and presentation of immunization safety data. Vaccine. 2011;29(3):599-612. doi: 10.1016/j.vaccine.2010.06.003.

6. Paybast S, Emami A, Koosha M, Baghalha F. Novel coronavirus disease (COVID-19) and central nervous system complications: what neurologist need to know. Acta Neurol Taiwan. 2020;29(1):24-31.

7. Dhadke SV, Dhadke VN, Bangar SS, Korade MB. Clinical profile of Guillain Barre syndrome. J Assoc Physicians India. 2013;61(3):168-72.

8. Nyati KK, Nyati R. Role of Campylobacter jejuni infection in the pathogenesis of Guillain-Barré syndrome: an update. Biomed Res Int. 2013;2013:852195. doi: 10.1155/2013/852195.
9. Zhao H, Shen D, Zhou H, Liu J, Chen S. Guillain-Barré syndrome associated with SARS-CoV-2 infection: causality or coincidence? Lancet Neurol. 2020;19(5):383-4. doi: 10.1016/ s1474-4422(20)30109-5.

10. Sedaghat Z, Karimi N. Guillain Barre syndrome associated with COVID-19 infection: a case report. J Clin Neurosci. 2020;76:233-5. doi: 10.1016/j.jocn.2020.04.062.

11. Virani A, Rabold E, Hanson T, Haag A, Elrufay R, Cheema $\mathrm{T}$, et al. Guillain-Barré Syndrome associated with SARSCoV-2 infection. IDCases. 2020;20:e00771. doi: 10.1016/j. idcr.2020.e00771.

12. Toscano G, Palmerini F, Ravaglia S, Ruiz L, Invernizzi P, Cuzzoni MG, et al. Guillain-Barré syndrome associated with SARS-CoV-2. N Engl J Med. 2020. doi: 10.1056/ NEJMc2009191.

13. McGonagle D, Sharif K, O'Regan A, Bridgewood C. Interleukin-6 use in COVID-19 pneumonia related macrophage activation syndrome. Autoimmun Rev. 2020;19(6):102537. doi: 10.1016/j.autrev.2020.102537. 